\title{
Sero-epidemiological evaluation of malaria transmission in The Gambia before and after mass drug administration
}

Lindsey $\mathrm{Wu}^{1{ }^{*+}}$, Julia Mwesigwa ${ }^{2 \dagger}$, Muna Affara ${ }^{3}$, Mamadou Bah², Simon Correa ${ }^{2}$, Tom Hall ${ }^{4}$, Susheel K. Singh ${ }^{5,6}$, James G. Beeson ${ }^{7,8,9}$, Kevin K. A. Tetteh ${ }^{1}$, Immo Kleinschmidt ${ }^{10,11}$, Umberto D'Alessandro ${ }^{2}$ and Chris Drakeley ${ }^{1}$

\begin{abstract}
Background: As The Gambia aims to achieve malaria elimination by 2030, serological assays are a useful surveillance tool to monitor trends in malaria incidence and evaluate community-based interventions.

Methods: Within a mass drug administration (MDA) study in The Gambia, where reduced malaria infection and clinical disease were observed after the intervention, a serological sub-study was conducted in four study villages. Spatio-temporal variation in transmission was measured with a panel of recombinant $P f$ antigens on a multiplexed bead-based assay. Village-level antibody levels were quantified as under-15 sero-prevalence, sero-conversion rates, and age-adjusted antibody acquisition rates. Antibody levels prior to MDA were assessed for association with persistent malaria infection after community chemoprophylaxis.

Results: Seasonal changes in antibodies to Etramp5.Ag1 were observed in children under 15 years in two transmission settings - the West Coast and Upper River Regions (4.32\% and 31.30\% Pf prevalence, respectively). At the end of the malaria season, short-lived antibody responses to Etramp5.Ag1, GEXP18, HSP40.Ag1, EBA175 RIII-V, and Rh2.2030 were lower amongst 1-15 year olds in the West Coast compared to the Upper River, reflecting known differences in transmission. Prior to MDA, individuals in the top 50th percentile of antibody levels had two-fold higher odds of clinical malaria during the transmission season, consistent with previous findings from the Malaria Transmission Dynamics Study, where individuals infected before the implementation of MDA had two-fold higher odds of re-infection postMDA.

Conclusions: Serological markers can serve dual functions as indicators of malaria exposure and incidence. By monitoring age-specific sero-prevalence, the magnitude of age-stratified antibody levels, or identifying groups of individuals with above-average antibody responses, these antigens have the potential to complement conventional malaria surveillance tools. Further studies, particularly cluster randomised trials, can help establish standardised serological protocols to reliably measure transmission across endemic settings.
\end{abstract}

Keywords: Malaria, Serology, Mass drug administration, Surveillance

\footnotetext{
* Correspondence: lindsey.wu@lshtm.ac.uk

${ }^{+}$Lindsey Wu and Julia Mwesigwa are co-first authors.

'Faculty of Infectious Tropical Diseases, Department of Infection Biology,

London School of Hygiene and Tropical Medicine (LSHTM), London WC1E

7HT, UK

Full list of author information is available at the end of the article
}

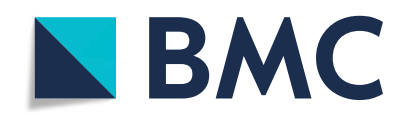

(- The Author(s). 2020 Open Access This article is licensed under a Creative Commons Attribution 4.0 International License, which permits use, sharing, adaptation, distribution and reproduction in any medium or format, as long as you give appropriate credit to the original author(s) and the source, provide a link to the Creative Commons licence, and indicate if changes were made. The images or other third party material in this article are included in the article's Creative Commons licence, unless indicated otherwise in a credit line to the material. If material is not included in the article's Creative Commons licence and your intended use is not permitted by statutory regulation or exceeds the permitted use, you will need to obtain permission directly from the copyright holder. To view a copy of this licence, visit http://creativecommons.org/licenses/by/4.0/. The Creative Commons Public Domain Dedication waiver (http://creativecommons.org/publicdomain/zero/1.0/) applies to the data made available in this article, unless otherwise stated in a credit line to the data. 


\section{Background}

In malaria elimination settings, heterogeneity and hotspots of transmission are increasingly prevalent as disease burden declines [1-5]. At low transmission, large proportions of the population can remain malaria free for years, while subpopulations experience multiple episodes $[3,4,6]$. This presents significant challenges for the implementation of malaria interventions and clinical trials designed to evaluate them $[7,8]$; if untargeted, residual transmission is likely to persist [5, 9-11]. Therefore, understanding why malaria has significantly changed in some settings, but remains unyielding in others, will be critical for guiding investments in malaria control in sub-Saharan Africa [12, 13].

The Gambia has a long history of research on the heterogeneity of malaria in West Africa. Entomological and clinical data have shown spatial variation in malaria infections within $2 \mathrm{~km}$ of mosquito breeding sites, where immune differences between households were hypothesised to drive differences in clinical outcomes [14]. Studies in The Gambia have also demonstrated the impact of insecticide-treated bed nets on childhood mortality [15, 16], with additional reductions in clinical malaria when combined with chemoprophylaxis [17]. Subsequently, there have been rapid declines in incidence through the scale-up of control interventions-improved diagnosis and treatment, distribution of long-lasting insecticidal nets, indoor residual spraying, and seasonal malaria chemoprevention. However, micro-epidemiological variations in transmission remain [18, 19], which are increasingly relevant as The Gambia aims for malaria elimination by 2030. Sufficiently sensitive diagnostics will be critical to reach this target, helping to identify foci of transmission and target interventions.

Serological studies in The Gambia have described country-wide heterogeneities in malaria transmission. School surveys have found strong correlations between sero-prevalence and microscopy-detectable parasitaemia [20]. More recently, studies based on data from Uganda and Mali have identified several serological markers of Plasmodium falciparum (Pf) malaria exposure that are able to predict clinical infection in the previous year with a high degree of accuracy [21]. These measures of sero-incidence have the potential to supplement existing surveillance tools to monitor transmission and evaluate the effectiveness of community interventions.

While serology has been used in research settings to measure malaria transmission for some time, standardised antigen panels for routine surveillance have yet to be established. Furthermore, gaps in our understanding of how antibody levels reflect changes in transmission still remain. Therefore, this study evaluates the use of antibody responses as a measure of malaria exposure and incidence, with the aim to inform the future design of surveillance strategies. We used serological markers to measure spatio-temporal variation in transmission in a subset of four study villages from the Malaria Transmission Dynamics Study in The Gambia, which assessed epidemiological trends in six village pairs [18, 19], followed by 2 years of mass drug administration (MDA) with dihydroartemisnin-piperaquine (DHA-PQ) [22]. A panel of recombinant $P f$ antigens was used to quantify antibody levels with a multiplexed immuno-assay. In our previous analysis in The Gambia, a number of targets in this antigen panel were found to be highly correlated with clinical and asymptomatic infection at the individual, household, and village level [23], and were also able to measure seasonal and geographical differences in transmission. This study builds on these findings to develop standardised methods for assessing populationlevel changes in antibody responses as a proxy for malaria transmission. Village serological profiles were used to describe seasonal and geographical variation in antibody responses, and the association between antibody levels prior to MDA and persistent malaria infection during the transmission season after MDA was also estimated.

\section{Methods}

\section{Data and sampling}

A prospective cohort study was conducted from 2013 to 2015 in six village pairs across five administrative regions from the West Coast Region (WCR) to the Upper River Region (URR). Pf prevalence as measured by polymerase chain reaction (PCR) ranged from $3.61 \%$ in the West Coast Region to $19.6 \%$ in the Upper River Region. As previously described by Mwesigwa et al. [19], the study aimed to understand the dynamics of malaria infection and the impact of annual MDA. All residents aged more than 6 months were enrolled. Monthly surveys were conducted throughout the transmission season (June to December), and in the dry season (April 2014) before MDA was implemented. In 2014 and 2015, one round of MDA was conducted, with DHA-PQ administered to individuals aged between 6 months and 75 years, according to weight-based dosing guidelines, over 6 to 14 days between May and June in the six pairs of study villages. Outcomes included incidence of clinical disease, prevalence of $P f$ infection measured by PCR, and factors associated with infection post-MDA.

Blood samples were collected by finger prick for haemoglobin measurement, blood smear for malaria diagnosis by microscopy, and molecular and serological analysis by dried blood spot (DBS) on filter paper (Whatman 3 Corporation, Florham Park, NJ, USA). Clinical malaria cases were identified by passive case detection (PCD) at local health facilities or in villages by study nurses; clinical malaria was defined as history of 
fever in the previous $24 \mathrm{~h}$ or axillary temperature $\geq$ $37.5^{\circ} \mathrm{C}$ and a positive rapid diagnostic test (RDT) result (Paracheck Pf, Orchid Biomedical System, India).

Serological analysis included all available samples from the West Coast Region in Besse and N'Demban from surveys at the start of the malaria transmission season in July $2013(N=530)$ and at the end of the season in December $2013(N=522)$. In the Upper River Region, analysis included all samples collected in Njayel and Madina Samako in July $2013(N=769)$, December $2013(N=$ 626), April (dry season) 2014 $(N=797)$, and December 2014 $(N=733)$. These regions are at the extreme of transmission intensity found in The Gambia-low transmission in the West Coast Region and moderate transmission in the Upper River Region. Samples from clinical PCD cases were linked by study participant identification code to samples from the same individuals collected during routine monthly surveys. Samples collected as part of the Malaria Transmission Dynamics Study and subset of samples for serological analysis are described in Fig. 1.

\section{Laboratory procedures}

A full description of laboratory methods, including antigen amino acid range, selection, and expression platform, is detailed in Wu et al. [24] and Mwesigwa et al. [25]. Briefly, serum samples were eluted from $6 \mathrm{~mm}$ DBS (8 $\mathrm{LL}$ whole blood equivalent) and prepared as a 1:500 dilution. Two wells on each plate containing only antigen-coupled beads and sample buffer were included to measure background signal. A pool of 22 serum samples from malaria hyper-immune individuals in The Gambia were used as positive controls in a 6-point 5- fold serial dilution (1:10-1:31,250) and plasma samples from European malaria-naive adults (1:500 dilution) as negative controls. Serum samples were processed on the Luminex MAGPIX, with mean fluorescence intensity (MFI) values between plates normalised according to the protocol described in Wu et al. [24].

For diagnostic PCR, DNA was extracted from three 6mm DBS ( $4 \mu \mathrm{L}$ whole blood equivalent) using the automated QIAxtractor robot (Qiagen). Negative and positive (3D7) controls were included to control for cross contamination and DNA extraction efficiency, respectively. Extracted DNA was used in a nested PCR, amplifying multi-copy Plasmodium ribosomal RNA gene sequences using genus- and species-specific primers. All PCR products were run using the QIAxcel capillary electrophoresis system (Qiagen).

\section{Statistical analyses}

Antibody responses were summarised at village level and used to describe geographical differences in transmission between the West Coast Region (low transmission) and the Upper River Region (moderate-high transmission). Within each region, temporal changes were assessed using antibody responses at the start and end of transmission season (July and December 2013) and the dry season (April 2014), represented with the methods as summarised below.

\section{Sero-prevalence and sero-conversion rate}

For antigens associated with longer-lived antibody responses [26-29] - P. falciparum merozoite surface antigen 1 19-kDa carboxy-terminal region (PfMSP1 19 ), $P$. falciparum apical membrane antigen 1 (PfAMA1), and P. falciparum glutamate rich protein (PfGLURP.R2) - the

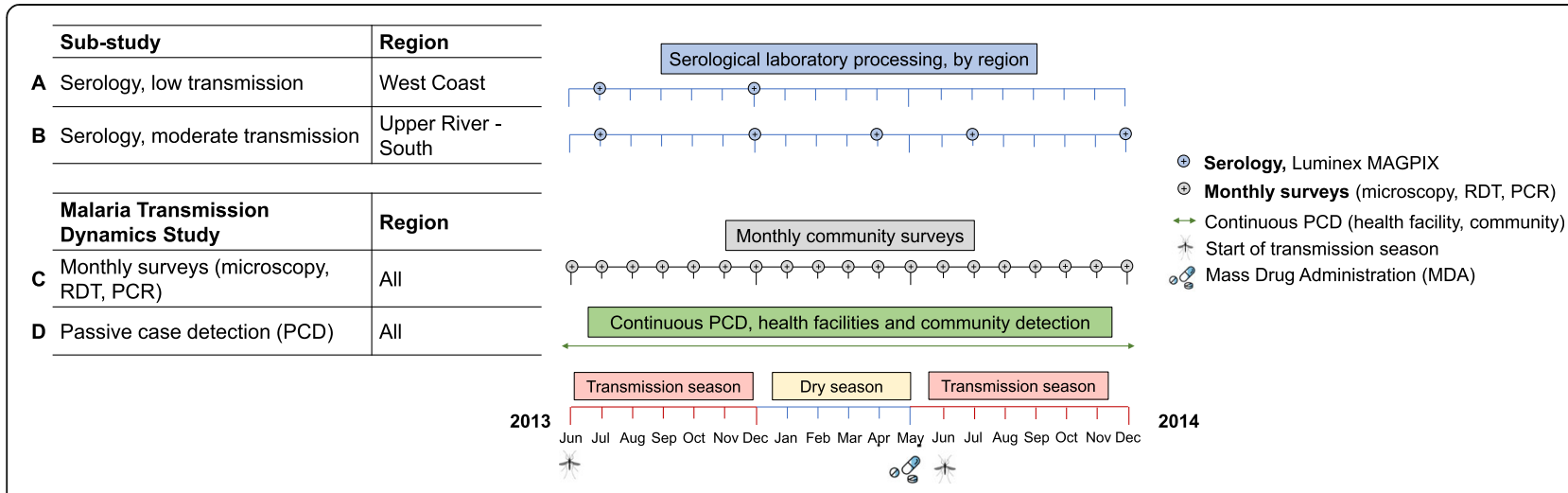

Fig. 1 Study timelines. Malaria Transmission Dynamics Study timeline shown in grey and green. Serological study timeline shown in blue for the West Coast Region and the Upper River Region (low and moderate transmission settings, respectively). Samples for serological analysis, shown in blue, were processed on the Luminex MAGPIX. Samples from monthly surveys (grey) were analysed using microscopy, rapid diagnostic tests (RDTs), and polymerase chain reaction (PCR). As part of the Malaria Transmission Dynamics Study, one round of mass drug administration (MDA) was administered from May to June in both 2014 and 2015 (2015 not shown as no samples from this year were used for serological analysis). Transmission season (shown in red) is approximately June to December each year, and dry season from approximately January to May (shown in yellow) 
distribution of MFI values for all serological samples was characterised with a two-component Gaussian mixture model to estimate the distributions of negative and positive antibody levels. Sero-positivity thresholds were defined as the mean log MFI plus two standard deviations of the negative distribution [30]. For antigens associated with shorter-lived antibodies [21,31]-early transcribed membrane protein 5 (Etramp5.Ag1), gametocyte export protein 18 (GEXP18), heat shock protein 40 (HSP40.Ag1), erythrocyte binding antigen 175 RIII-V (EBA175), and reticulocyte binding protein homologue 2 (Rh2.2030) - sero-positivity thresholds were defined by the mean log MFI plus three standard deviations of 71 malaria-naïve European blood donors used as negative controls.

Age-adjusted sero-conversion rates (SCRs), the annual rate at which sero-negative individuals become seropositive, were estimated for antigens associated with long-lived antibody response (PfMSP1 19, PfAMA1, PfGLURP.R2). A reverse catalytic model was fitted to age-adjusted sero-positivity data using maximum likelihood methods [28]. A common sero-reversion rate for each antigen was assumed across all villages, which was estimated based on fitting a single sero-catalytic model to all individuals and fixing the sero-reversion rate in subsequent model fits. Additionally, sero-prevalence was estimated for children aged 1-15 years. Given the lower likelihood of long-lived antibodies from previous malaria exposure, sero-positivity in this age group is more likely to reflect recent infection [20,32]. Seasonal differences in sero-prevalence were assessed using a two-proportion $z$ test, where standard errors were based on a pooled sample population size and differences in seroprevalence with a significance level of 0.05 reflected by a 95\% CI range that excluded zero.

\section{Age-dependent antibody acquisition}

Antibody acquisition models [33, 34] were used to estimate age-dependent changes in antibody levels. Two variants of the model were used-one assuming a constant rate of increasing antibody levels with age and one assuming differing antibody acquisition rates between age groups (Additional file 1 - Supplementary methods). Area Under the Antibody Acquisition Curve (AUC) values were calculated based on the model fit for each village and survey month, representing cumulative antibody levels across all ages [35]. Within-region AUCs were compared between the start and end of transmission season as well as between regions at each time point. The strength of evidence for observed differences is presented as $p$ values, derived from the posterior distributions of predicted antibody levels over two different specified age ranges (all ages or ages 1-15 years).
Dry season antibody levels and odds of infection post-MDA Individual antibody levels in April 2014 prior to MDA were assessed by comparing observed and expected MFI values as predicted by the antibody acquisition fit for individuals in the Upper River Region. For individuals with above-average MFI values for their age group, the difference between the observed and expected log MFI was calculated and classified to below or above median of residual MFI antibody response. Logistic regression was used to estimate the odds of clinical malaria (passively detected via the health facility or study nurses in the community) or asymptomatic $P f$ infection (actively detected using PCR from monthly survey samples) during the transmission season following MDA (October to December 2014) amongst individuals below and above median residual dry season antibody levels, compared to individuals at or below expected antibody responses, allowing for clustering at the household/compound. Multivariate analyses also adjusted for age, LLIN use, and MDA adherence using generalised linear mixedeffects models with the 'glm' and 'glmer' functions in the 'Ime4' v1.1-21 package in R version 3.6.1.

\section{Results}

Sero-prevalence in children by geographical region and transmission season

Variation in sero-prevalence between geographical region and transmission season differed by antigen. Specifically, between July and December (start and end of the transmission season), sero-prevalence to Etramp5.Ag1 in children aged 1-15 years in the West Coast Region increased by $4.8 \%$ (95\% CI $4.0-5.6$ ), by $3.1 \%$ (95\% CI $2.7-3.5$ ) for PfMSP $1_{19}$, by $2.9 \%$ (95\% CI 2.3-3.6) for PfGLURP.R2, and by $2.2 \%$ (95\% CI $0.9-3.5)$ for GEXP18 (Table 1, Fig. 2, Additional file 1 - Supplementary Table 1). In the Upper River Region, there was statistically strong evidence for increases in under-15 sero-prevalence between July and December for all antigens (Additional file 1 - Supplementary Table 1). Mean sero-prevalence in the Upper River Region in December 2014 (the transmission season after MDA) was lower for PfMSP1 19 , PfAMA1, PfGLURP.R2, Etramp5.Ag1, Rh2.2030, and EBA175, compared to December 2013 before implementation of MDA (Additional file 1 Supplementary Table 1).

\section{Sero-conversion rate between geographical regions and transmission seasons}

Differences in sero-conversion rate between geographical region and transmission season varied by antigen (Fig. 3, Additional file 1 - Supplementary Table 2). At both the start (July) and end (December) of the 2013 transmission season, sero-conversion rates for $P f \mathrm{MSP} 1_{19}$, PfAMA1, and PfGLURP.R2 were higher in the Upper River Region than the West Coast Region. Seasonal differences in sero- 
Table 1 Sero-prevalence in children aged 1-15 years by antigen, geographical region, and transmission season. Mean seroprevalence estimates are shown for the West Coast Region (WCR) for July 2013 and December 2013, and the Upper River Region (URR) for July 2013, December 2013, April 2014, and December 2014. Mean and 95\% confidence intervals (parentheses) are shown as percentages

A. Ages 1-15 years sero-prevalence (95\% Cl)-short-lived antibody responses

\section{Etramp5.Ag1}

West Coast Region (WCR)

$$
\text { July } 2013(n=309)
$$

December $2013(n=315)$

$$
\begin{aligned}
& 3.2 \%(1.9-4.5) \\
& 8.0 \%(6.2-9.9)
\end{aligned}
$$

Upper River Region (URR)

$$
\begin{aligned}
& \text { July } 2013(n=431) \\
& \text { December } 2013(n=387)
\end{aligned}
$$

April $2014(n=489)$

December $2014(n=434)$
GEXP18

$7.5 \%(5.6-9.4)$
$9.8 \%(7.7-11.8)$

$16.4 \%(14.1-18.7)$

$22.5 \%(20.0-25.1)$

$20.7 \%(18.5-22.9)$

$25.5 \%(22.9-28.1)$

\section{HSP40.Ag1}

$3.8 \%(2.4-5.1)$

$4.6 \%(3.1-6.1)$

$7.2 \%(5.5-8.8)$

$14.4 \%(12.2-16.5)$

$14.1 \%(12.1-16.0)$

$16.0 \%(13.8-18.2)$
Rh2.2030

$1.5 \%(0.6-2.4)$
$1.9 \%(1.0-2.9)$
$6.8 \%(5.2-8.3)$
$17.1 \%(14.8-19.4)$
$14.3 \%(12.4-16.2)$
$13.2 \%(11.2-15.3)$

EBA175

\author{
$1.7 \%(0.8-2.6)$
}

$1.1 \%(0.4-1.9)$

5.3\% (3.9-6.7)

$10.5 \%(8.7-12.4)$

$9.3 \%(7.7-10.9)$

$8.6 \%(6.9-10.3)$

B. Ages 1-15 years $(95 \% \mathrm{Cl})$-long-lived antibody responses

\section{PfMSP1 $_{19}$}

West Coast Region (WCR)

July $2013(n=309)$

December $2013(n=315)$

Upper River Region (URR)

$\begin{array}{ll}\text { July } 2013(n=431) & 3.4 \%(2.2-4.5) \\ \text { December } 2013(n=387) & 12.8 \%(10.7-14.8) \\ \text { April } 2014(n=489) & 8.5 \%(7.0-10.1) \\ \text { December } 2014(n=434) & 9.3 \%(7.5-11.0)\end{array}$

PfAMA1

$3.8 \%(2.4-5.1)$

$4.0 \%(2.7-5.4)$

$14.4 \%(12.2-16.6)$

$22.5 \%(20.0-25.1)$

$19.2 \%(17.0-21.4)$

$18.0 \%(15.7-20.3)$

\section{PfGLURP.R2}

$3.2 \%(1.9-4.5)$

$6.1 \%(4.5-7.8)$

$12.1 \%(10.1-14.1)$

$20.8 \%(18.3-23.3)$

$18.7 \%(16.5-20.8)$

$16.5 \%(14.3-18.7)$

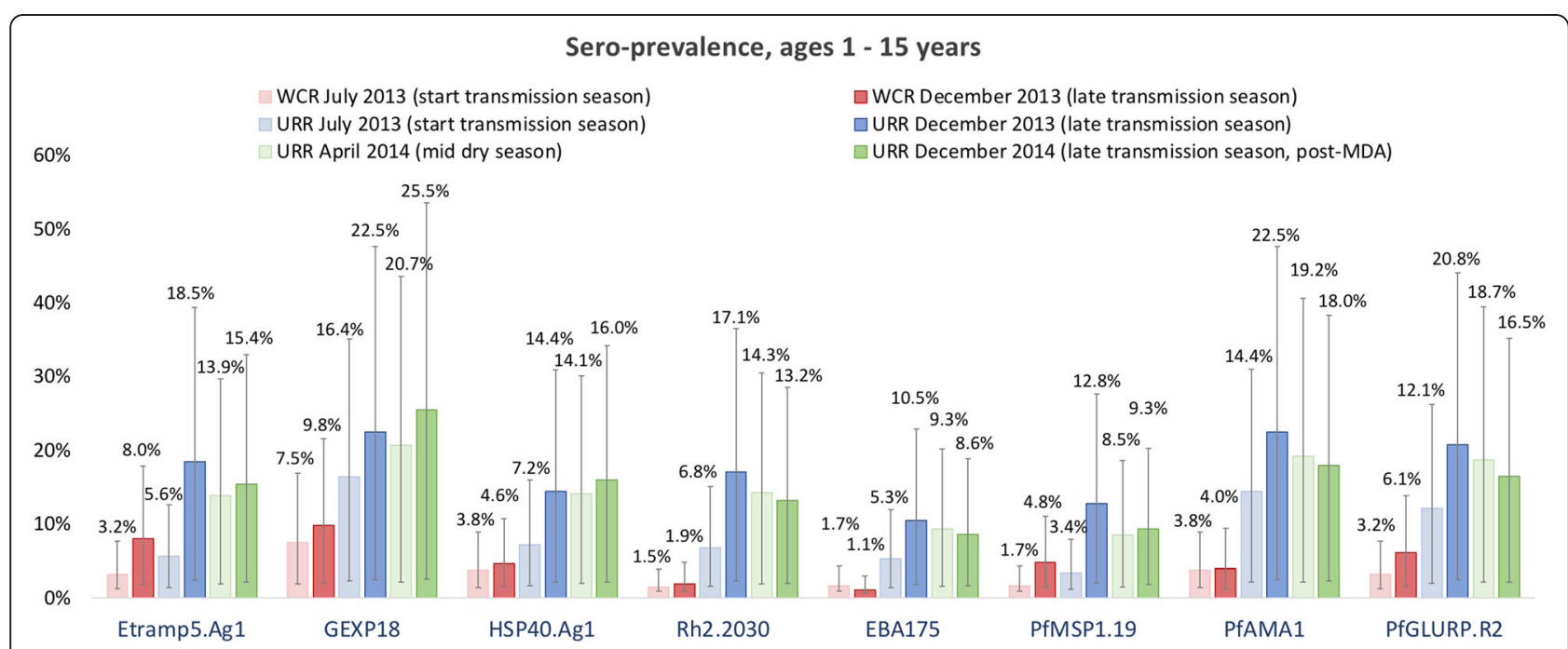

Fig. 2 Sero-prevalence in children ages 1-15 years by antigen, geographical region, and transmission season. Mean sero-prevalence estimates are shown for the West Coast Region (WCR) for July 2013 (light red) and December 2013 (dark red), and the Upper River Region (URR) for July 2013 (light blue), December 2013 (dark blue), April 2014 (light green), and December 2014 (dark green), and 95\% Cls are indicated by the vertical bars 


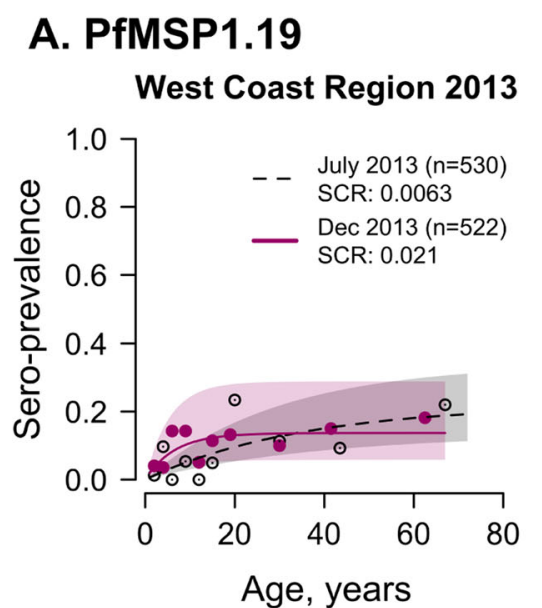

\section{B. PfAMA1}

West Coast Region 2013

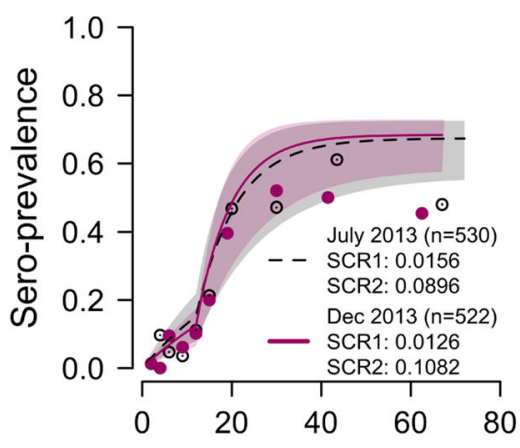

Age, years

\section{PfGLURP.R2}

West Coast Region 2013

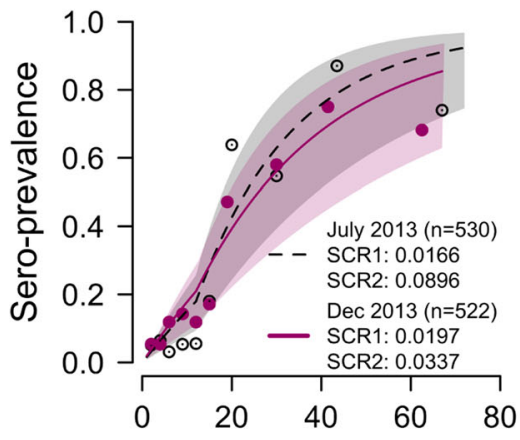

Age, years
Upper River Region 2013

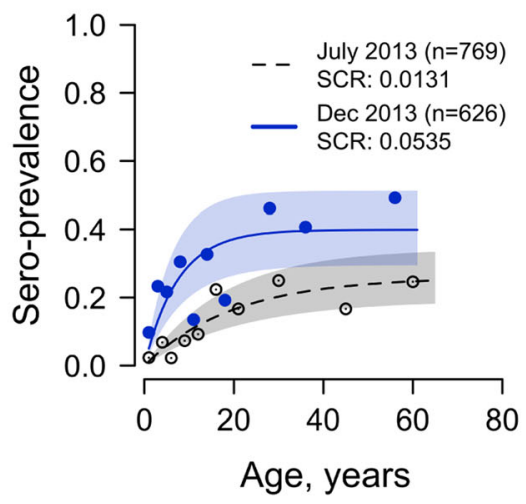

Upper River Region 2013

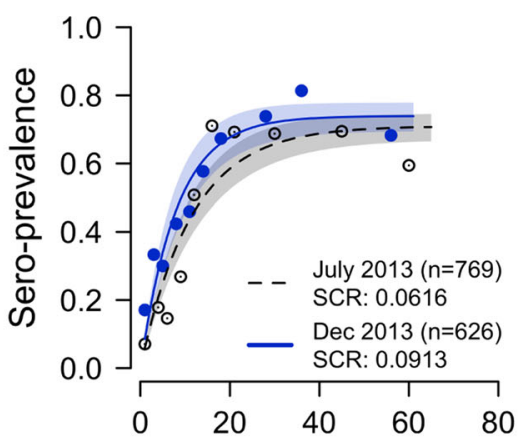

Age, years

Upper River Region 2013

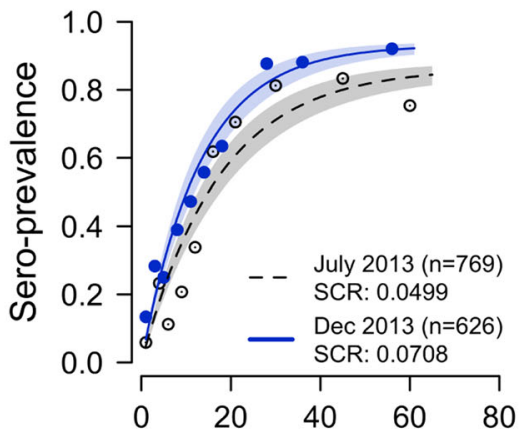

Age, years
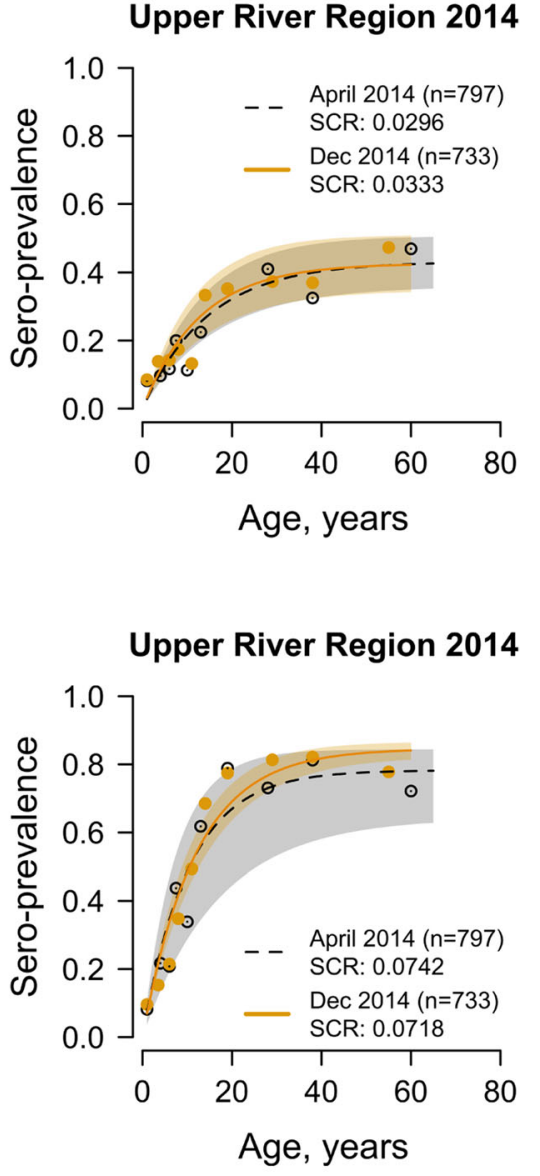

Upper River Region 2014

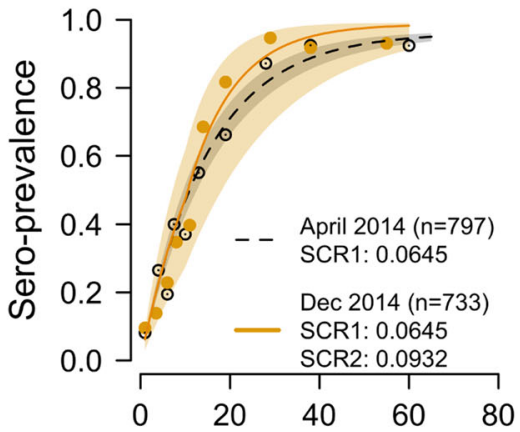

Age, years

Fig. 3 PFMSP1.19, PFAMA1, and PFGLURP.R2 sero-conversion rates by transmission season and geographical region. Mean and 95\% confidence intervals of sero-prevalence for each age group are shown as circles and vertical lines, respectively. The mean fit of the reverse catalytic model is shown as a solid line for the end of the transmission season (December 2013 and 2014) and as a dotted line for the dry season (April 2014) or start of the transmission season (July 2013). Shaded regions are the $95 \%$ credible interval of the model fit

conversion rate within the same region were also observed. In the West Coast Region, PfMSP1 19 seroconversion rate was three times higher in December 2013 $(0.0210,95 \%$ CI $0.0082-0.0536)$ than in July $2013(0.0063$,
95\% CI 0.0034-0.0115), while in the Upper River Region, $\mathrm{PfMSP}_{19}$ sero-conversion rate was four times higher in December $2013(0.0535,95 \%$ CI $0.0337-0.0849)$ than in July 2013 (0.0131, 95\% CI 0.0088-0.0194). However, for 
PfAMA1 and PfGLURP.R2, seasonal differences in seroconversion rates were only observed in the Upper River Region, where PfAMA1 sero-conversion rate in December 2013 was 0.0913 (95\% CI $0.0735-0.1135$ ) compared to $0.0616(95 \% \mathrm{CI} 0.0511-0.0743)$ in July 2013 and PfGLURP.R2 sero-conversion rate was 0.0708 (95\% CI 0.0605-0.0829) in December 2013 compared to 0.0499 (95\% CI 0.0427-0.0584) in July 2013. Sero-conversion rates for all three antigens were similar between April and December 2014. Increases in sero-prevalence in older age groups are not pronounced for markers associated with short-lived antibody responses, which is an underlying assumption when using sero-catalytic models. Therefore, antibody acquisition models are used in place of seroconversion rates to assess age-adjusted changes in antibody responses based on continuous data for markers of short-lived antibody responses.

\section{Age-adjusted antibody acquisition by geographical region and transmission season}

All serological markers associated with shorter-lived antibody responses (Etramp5.Ag1, GEXP18, HSP40.Ag1, EBA175, and Rh2.2030) showed higher antibody levels in 115 year olds in the Upper River Region compared to the West Coast Region at the end of the transmission season (Fig. 4, Additional file 1 - Supplementary Tables 3-7). In the Upper River Region, antibody responses to Etramp5.Ag1 increased between the start and end of the transmission season amongst individuals $1-15$ years $(p=0.002)$ (Additional file 1 - Supplementary Table 3). However, antibody levels in 1-15 year olds for HSP40.Ag1 decreased between the start and end of the transmission season in the West Coast Region $(p=0.01)$ (Additional file 1 - Supplementary Table 5). Antibody levels to GEXP18 amongst 1-15 year olds were also higher in the Upper River Region compared to the West Coast Region at the start of the transmission season $(p=0.03)$ (Additional file 1 - Supplementary Table 4).

For antigens associated with long-lived antibody responses (PfMSP1 19 , PfAMA1, and PfGLURP.R2), differences in ageadjusted antibody acquisition amongst 1-15 year olds were observed between the West Coast Region and Upper River Region at the end of the 2013 transmission season (December) (Fig. 5, Additional file 1 - Supplementary Tables 8-10). For $P f M S P 11_{19}$, differences in geometric mean antibody levels in children aged 1-15 years in the Upper River Region were higher at the end of the transmission season compared to the start of the season $(p=0.05)$ (Additional file 1 - Supplementary Table 8). However, no significant differences in antibody levels for PfAMA1 or PfGLURP.R2 were observed between the start and end of transmission season in the Upper River Region. There were no within-region differences in antibody responses to any of the antigens tested between the 2013 transmission season and the following dry season (April 2014).

\section{Association between pre-MDA antibody levels and post- MDA malaria infection}

Significant decreases in under-15 sero-prevalence between pre- and post-MDA transmission seasons (December 2013 vs. December 2014) were observed for nearly all antigens. The largest decreases were for PfAMA1 $(-4.5 \%, 95 \% \mathrm{CI}-$ 7.2, - 1.8), PfGLURP.R2 (-4.3\%, 95\% CI -6.7, - 1.8), Rh2.2030 (-3.9\%, 95\% CI - 5.9, - 1.9), PfMSP1 19 (-3.5\%, 95\% CI - 4.9, - 2.1), and Etramp5.Ag1 (- 3.1\%, 95\% CI - 5.4, - 0.9) (Additional file 1 - Supplementary Table 1). Based on a subset of samples from 706 individuals during the 2014 transmission season, individuals with above-average antibody levels in their age group during the dry season (April 2014) prior to the implementation of MDA had increased odds of clinical malaria in the 2014 transmission season (October to December) following MDA. After adjusting for age, LLIN use in the last $24 \mathrm{~h}$, and MDA compliance, individuals with high antibody levels to Etramp5.Ag1 had a twofold higher odds of clinical malaria (aOR 2.05, 95\% CI 1.12-3.77, $p=$ 0.02) (Fig. 6a, Additional file 1 - Supplementary Table 11). Dry season antibody levels to $\mathrm{Rh} 2.2030$ were also associated with a twofold increase in odds of clinical malaria (OR 2.13, 95\% CI 1.14-3.99, $p=0.02$ ) after MDA (Fig. 6a, Additional file 1 - Supplementary Table 15). While not statistically significant, mean odds ratios indicate an increased odds of clinical malaria for individuals with high antibody levels to a number of other antigens in the panel, including PfAMA1 (aOR 1.68, 95\% CI 0.91-3.10, $p=0.10$ ), EBA175 (aOR 1.64, 95\% CI 0.91-2.93, $p=0.10$ ), HSP40.Ag1 (aOR 1.54, 95\% CI $0.83-2.84, p=0.17$ ), and GEXP18 (aOR 1.49, 95\% CI 0.80$2.75, p=0.21$ ) (Additional file 1 - Supplementary Tables 17, 14,13 , and 12 respectively). There was a positive, but weaker and non-statistically significant, association between clinical malaria and high antibody responses to $P f M S P 1_{19}$ (aOR 1.06, 95\% CI 0.56-1.99, $p=0.86$ ) and PfGLURP.R2 (aOR 1.19, 95\% CI 0.59-2.39, $p=0.63$ ) (Additional file 1 - Supplementary Tables 16 and 18). Associations between dry season antibody levels and asymptomatic infection (defined as positive by PCR and negative by RDT) were not statistically significant for any antigens, but mean adjusted odd ratios indicate an increased odds of infection for individuals with high antibody levels to Rh2.2030 (aOR 1.60, 95\% CI 0.81-3.14, $p=$ 0.17), HSP40.Ag1 (aOR 1.64, 95\% CI 0.81-3.34, $p=0.17$ ), PfMSP1 $_{19}$ (aOR 1.22, 95\% CI 0.63-2.34, $p=0.56$ ), Etramp5.Ag1 (aOR 1.14, 95\% CI 0.68-1.91, $p=0.63$ ), and EBA175 (aOR 1.13, 95\% CI 0.57-2.26, $p=0.73$ ) (Fig. 6b, Additional file 1 - Supplementary Tables 15, 13, 16, 11, and 14, respectively).

\section{Discussion}

In this study, we build on previous studies evaluating individual- and household-level associations between concurrent clinical and asymptomatic malaria infection with serological responses to a panel of antigenic targets. This 
A. Etramp5.Ag1

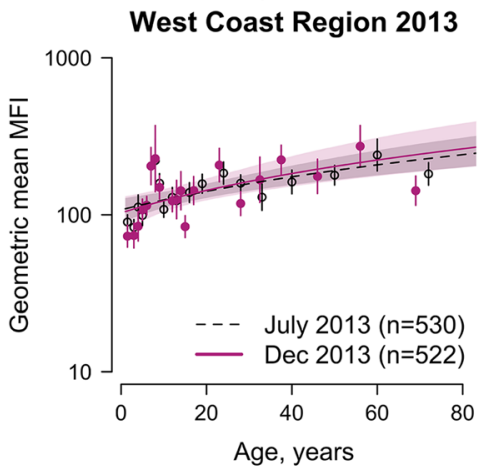

\section{B. GEXP18}

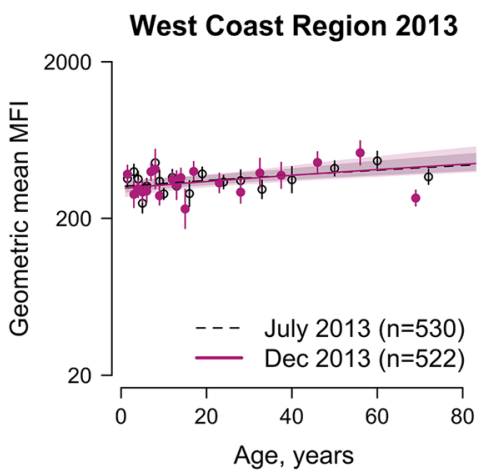

\section{HSP40.Ag1}

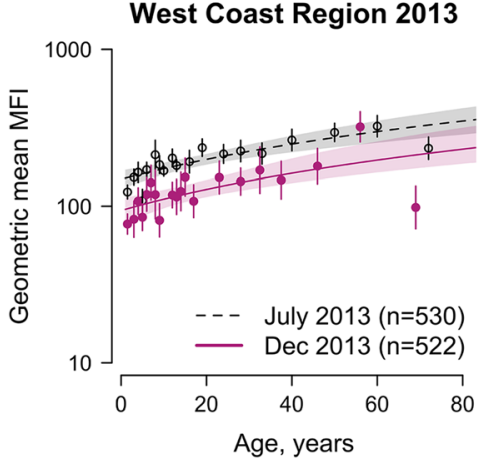

\section{Rh2.2030}

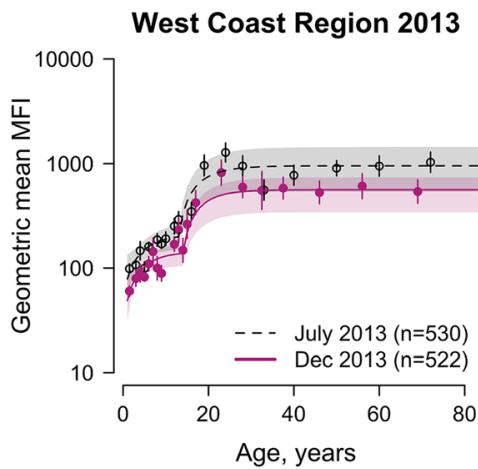

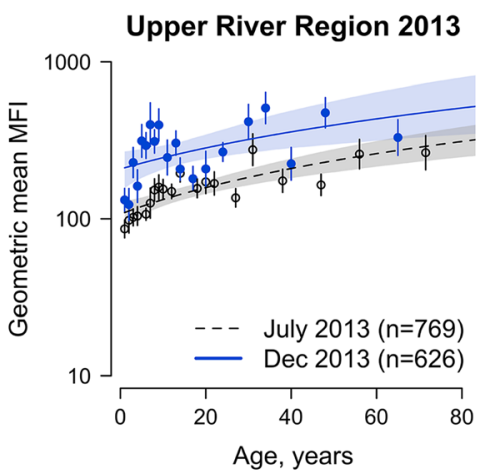
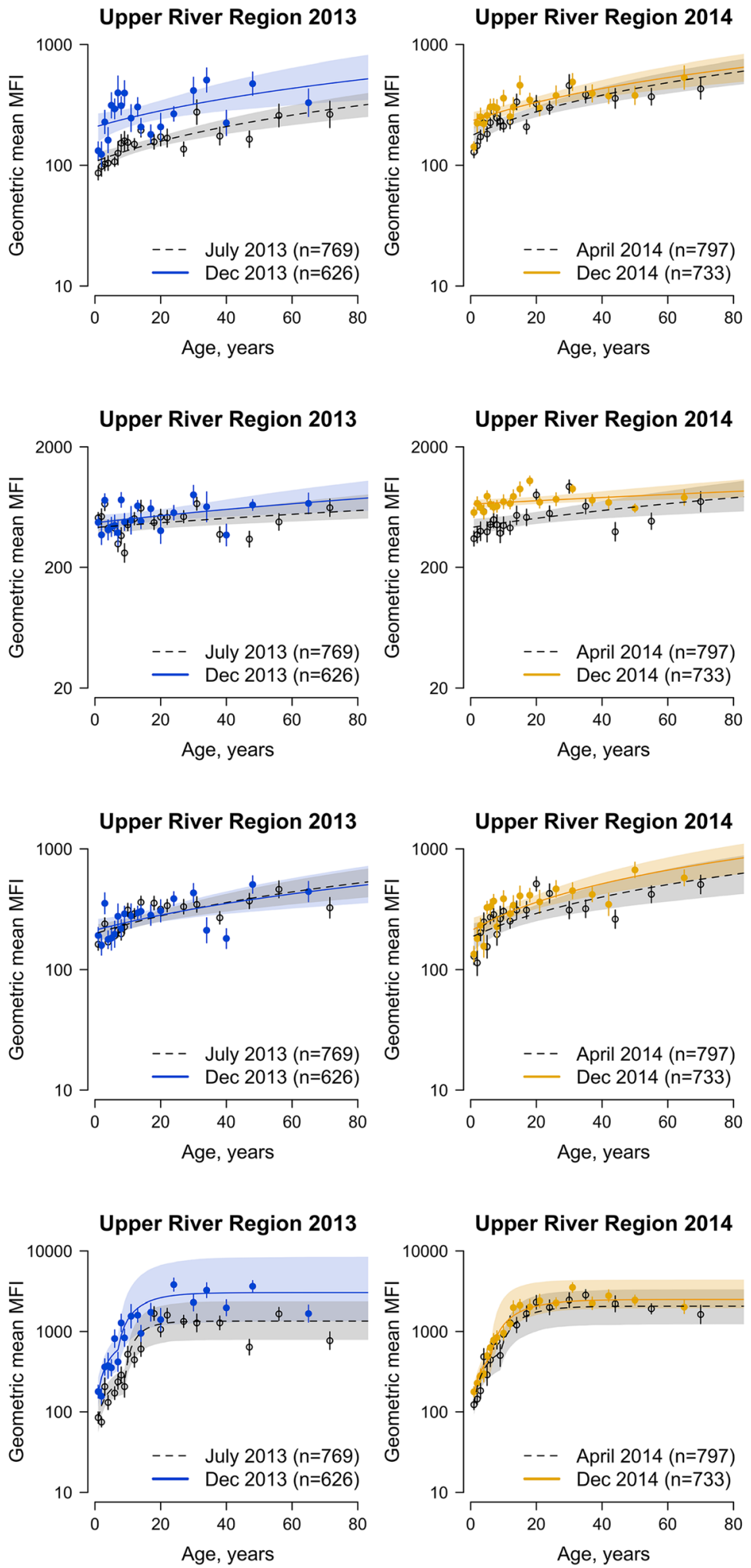

Fig. 4 Age-dependent antibody acquisition for Etramp5.Ag1, GEXP18, HSP40.Ag1, and Rh2.2030 by geographical region and transmission season. Mean and 95\% confidence intervals of geometric mean antibody levels for each age group are shown as circles and vertical lines, respectively. Median fit of the antibody acquisition model is shown as a solid line for the end of the transmission season (December 2013 and 2014) and as a dotted line for the dry season (April 2014) or start of the transmission season (July 2013). Shaded regions are the 95\% credible intervals of the model fit 


\section{A. EBA175}
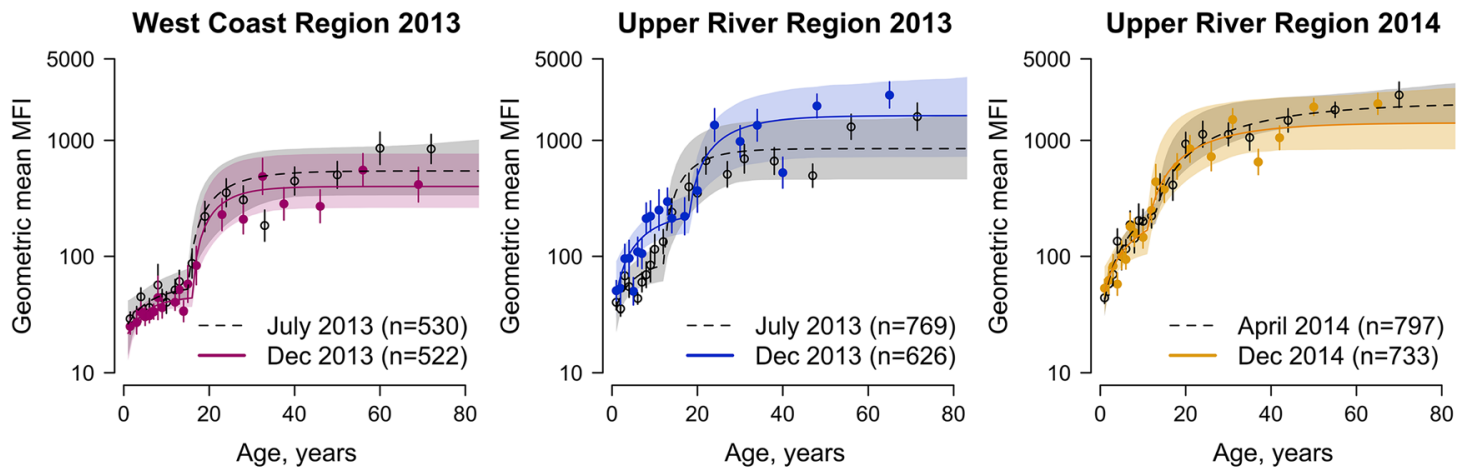

\section{B. PfMSP1.19}

West Coast Region 2013
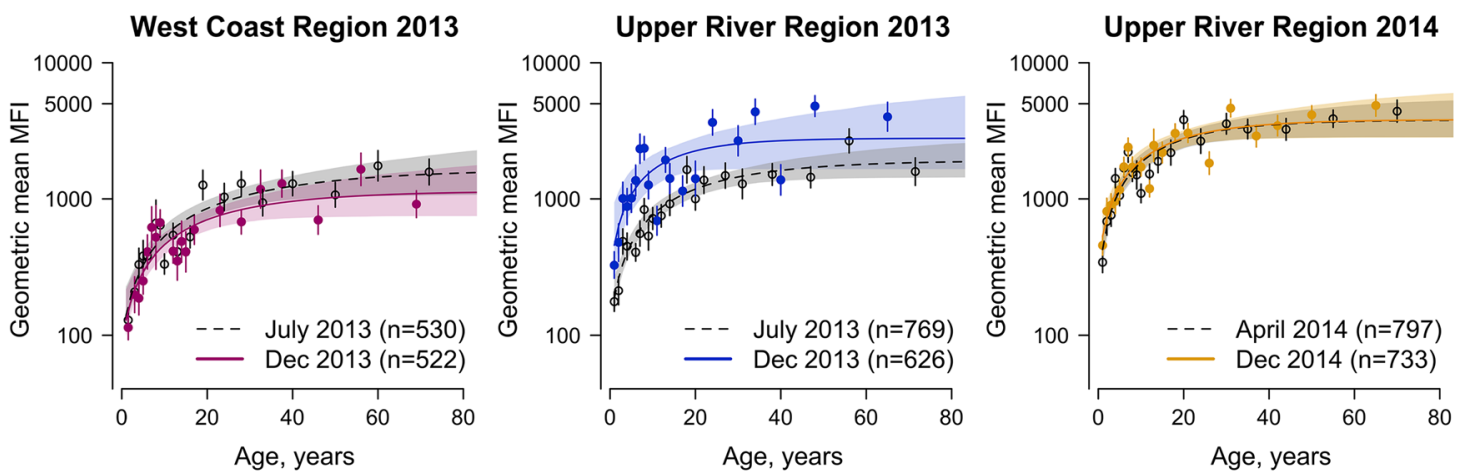

\section{PfAMA1}

West Coast Region 2013
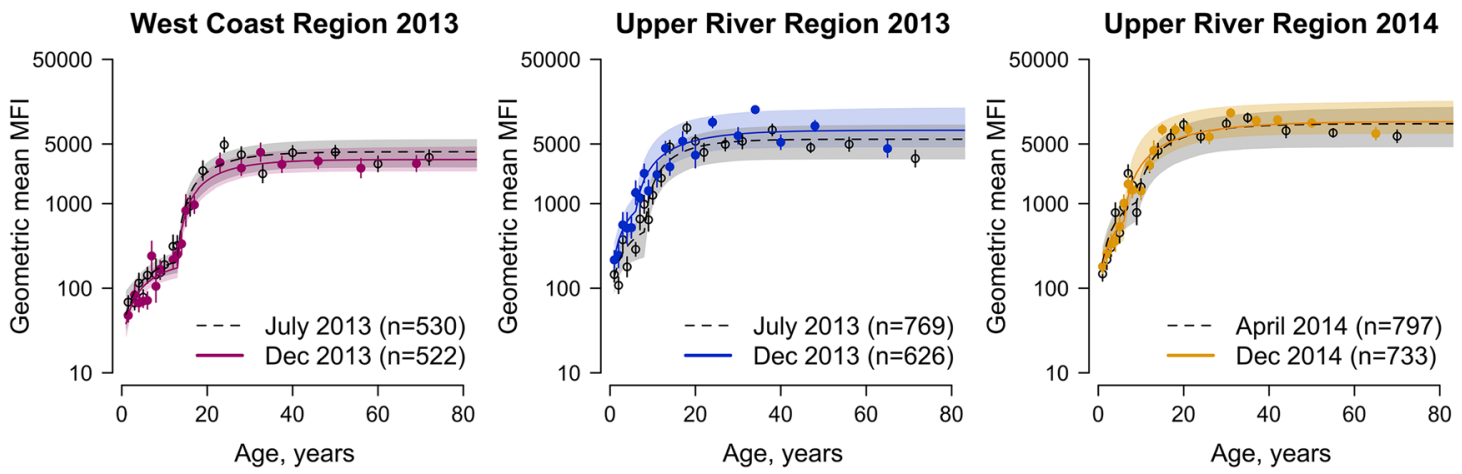

\section{PfGLURP.R2}

West Coast Region 2013
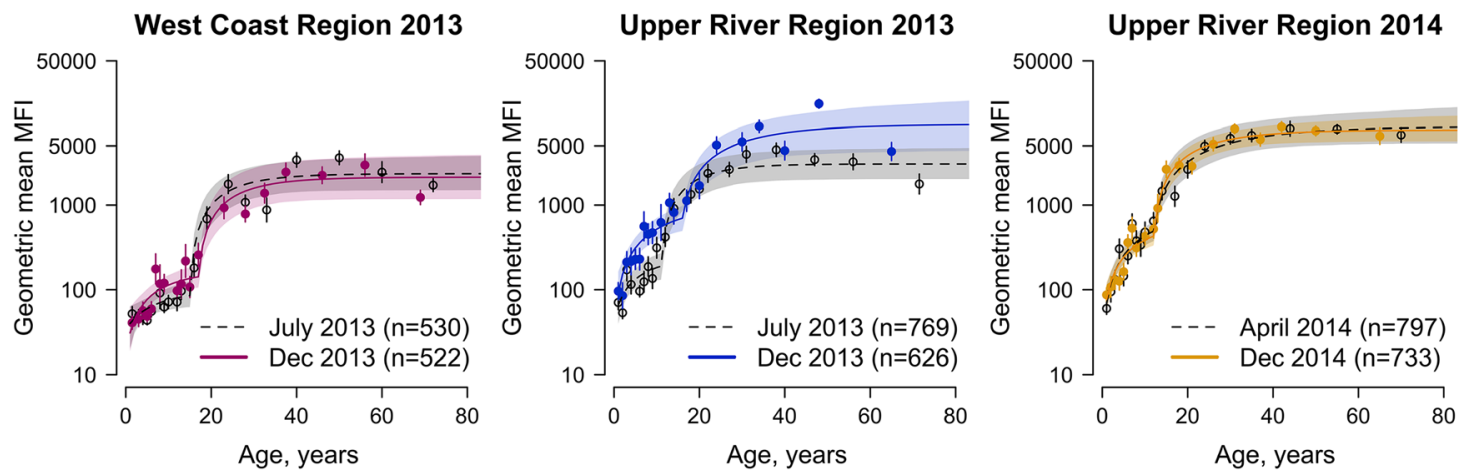

Fig. 5 Age-dependent antibody acquisition for EBA175, PfMSP1 ${ }_{19}$, PfAMA1, and PfGLURP.R2 by geographical region and transmission season. Mean and $95 \%$ confidence intervals of geometric mean antibody levels for each age group are shown as circles and vertical lines, respectively. Median fit of the antibody acquisition model is shown as a solid line for the end of the transmission season (December 2013 and 2014) and as a dotted line for the dry season (April 2014) or start of the transmission season (July 2013). Shaded regions are the $95 \%$ credible intervals of the model fit 


\section{A. Odds of clinical malaria by pre-MDA antibody level}

Percentile above age-adjusted mean MFI: <50th percentile, $>50$ th percentile

Reference: Individuals with at or below age-adjusted mean MFI

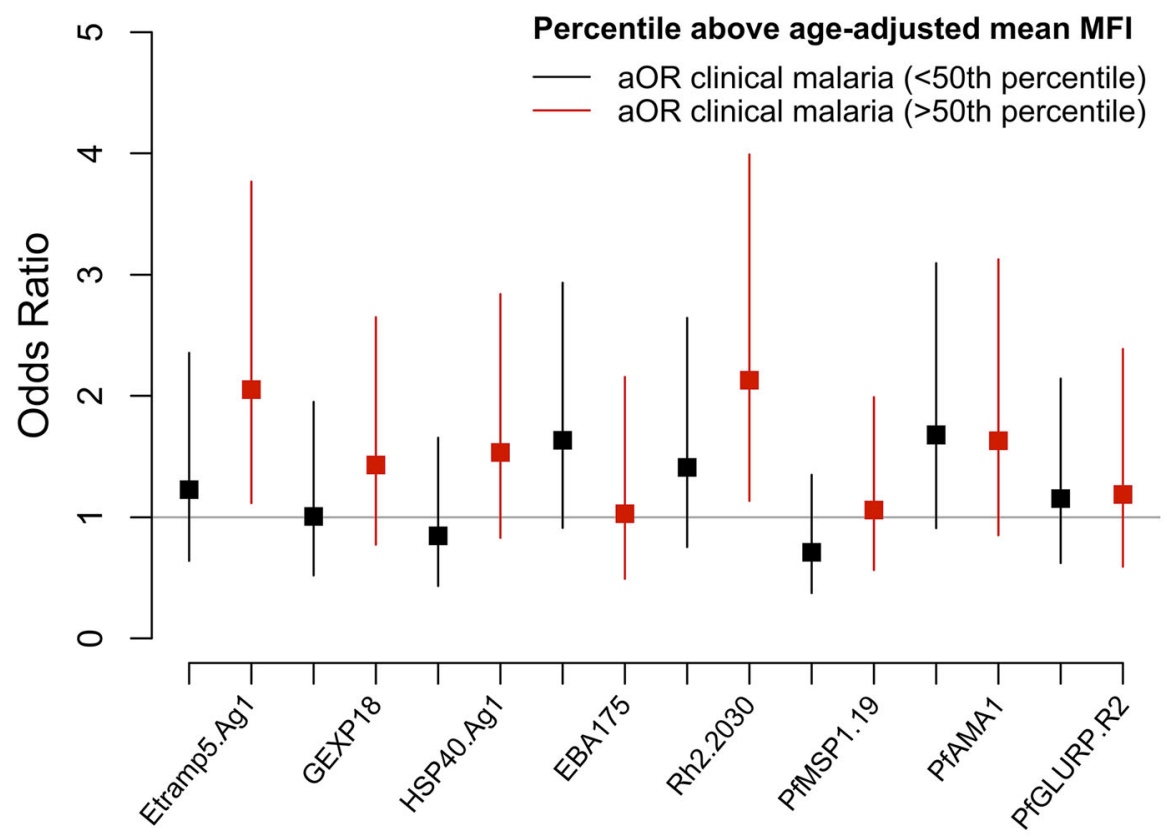

\section{B. Odds of asymptomatic infection by pre-MDA antibody level}

Percentile above age-adjusted mean MFI: <50th percentile, >50th percentile Reference: Individuals with at or below age-adjusted mean MFI

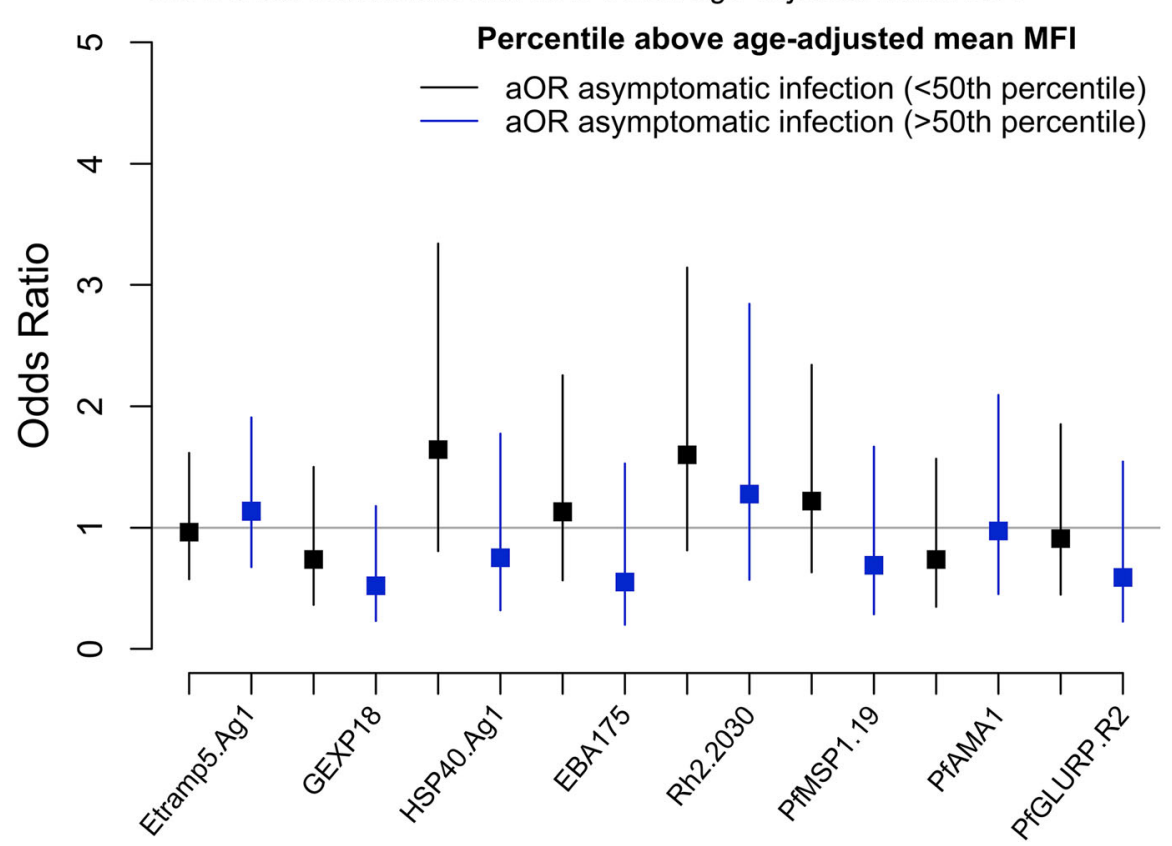

Fig. 6 Association of pre-MDA dry season (April 2014) antibody levels and odds of a clinical malaria or $\mathbf{b}$ asymptomatic infection, during transmission season post-MDA (December 2014). Odds ratios are adjusted for age, LLIN use, and MDA adherence $(n=706)$. Clinical malaria is defined as a clinical or RDT confirmed case, and asymptomatic infection is defined as a PCR-positive, but clinically or RDT-negative 
study extends upon these findings to develop serological methods for monitoring seasonal and geographical trends in transmission, tailored for potential integration into routine surveillance or trial evaluation. Spatiotemporal variations in serological responses were observed for several $P f$ antigens, likely reflecting changes in malaria incidence as well as residual antibodies due to prior infection. In moderate to high transmission settings, higher antibody levels in the dry season due to prior exposure are common. However, the rate at which protective antibodies develop varies by setting. Immunity to clinical malaria has been observed in children as young as 5 years $[36,37]$, while in other transmission settings, immunity may only develop after 10 to 15 years of exposure [38, 39]. Children can be a useful sentinel population for monitoring transmission, but the optimal age range for surveillance depends on the historical patterns of transmission governing population antibody responses. Most indicators and survey designs are associated with some bias affecting the accuracy of estimates. School surveys in South East Asia, where the distribution of malaria may be skewed towards older age groups, may better reflect sero-incidence due to less childhood exposure compared to sub-Saharan Africa. Serological surveillance protocols can therefore be combined with other routine metrics to counter potential sampling biases.

Differences in sero-conversion rates to $P f M S P 1_{19}$, PfAMA1, and PfGLURP.R2 were observed between geographical regions and between the start and end of the 2013 transmission season in the Upper River Region. However, seasonal differences in sero-conversion rates were not detected in the West Coast Region. Long-lived antibody responses typically reflect past exposure rather than incidence during a single transmission season. However, these markers have been shown to be sensitive to changes in transmission over longer periods of time in The Gambia [40]. Antibody acquisition models can detect more subtle differences in the magnitude of antibody levels as a proxy for variation or changes in parasite exposure. Five sero-incidence markers evaluated in this study-Etramp5.Ag1, GEXP18, HSP40.Ag1, EBA175, and Rh2.2030-detected geographical differences in antibody acquisition. Additionally, Etramp5.Ag1 and HSP40.Ag1 detected seasonal differences in highand low-transmission settings. These findings align with previous microarray studies, where Etramp5.Ag1, GEXP18, and HSP40.Ag1 were amongst the top 10 serological markers out of $856 P f$ antigens screened found to be most associated with recent episodes of clinical malaria in Uganda and Mali [21].

Between December 2013 and April 2014, antibody levels did not decline significantly, indicating that antibody decay probably occurs over a period longer than
4 months. This may be due to persistent asymptomatic parasitaemia or infections occurring late in the transmission season. In The Gambia, antibody decay in children has been observed for several antigens associated with protective immunity (PfAMA1, PfMSP2, PfMSP1, EBA175), with antibody half-lives estimated between 10 and 50 days [29, 41], and long-lived antibody secreting cells persisting for up to 4 years [29]. However, antibody half-lives vary between settings, ranging from 10 to 20 days in Kenya [42] and Ghana [29], 98 to 120 days in Nigeria for EBA175 and Rh4.2 [31], and up to 225 days in Cambodia [27] and 7 years in Thailand [26] for PfMSP1 $1_{19}$. However, these studies focus on a limited number of antigens. Estimates of antibody longevity for a larger range of antigens can help inform optimal sampling strategies for future serological surveillance using multiplex assay platforms. For example, studies in Mali have quantified antibody responses to over $2000 \mathrm{Pf}$ antigens on protein microarray, observing rapid declines in antibody levels within 6 months [43].

Above-average antibody levels in the dry season before MDA were associated with increased odds of clinical malaria following MDA. Associations were moderate for PfAMA1, EBA175, HSP40.Ag1, and GEXP18, but individuals with higher than average antibody levels against Etramp5.Ag1 and Rh2.2030 had a twofold higher odds of clinical malaria post-MDA. It is possible that serology can identify individuals who are infected during the dry season or experience a high frequency of exposure, leading to increased risk of clinical illness, despite remaining below the detection limit of other diagnostics. Similar associations were observed using parasitological endpoints, where individuals with $P f$ infection as measured by PCR in the dry season had increased odds of infection post-MDA [22]. While results were not statistically significant, mean odds ratios suggest some association between above-average serological responses in the dry season and asymptomatic infection as detected by PCR. This study may be limited by the smaller sample of asymptomatic infections $(n=55)$ compared to clinical cases $(n=87)$. Results may also indicate that dry season antibody levels for individuals who are later at risk of asymptomatic infection, while still higher than average, may be lower relative to those who develop clinical malaria. The threshold antibody levels that indicate increased risk of subsequent clinical malaria warrant further study. Given that this study was not designed specifically for the serological evaluation of MDA, analysis of a larger set of antigens or a grouping of antibody data based on antigen expression or function during the parasite life cycle may help delineate or categorise the wide range of responses with respect to malaria exposure, incidence, or immunity. Prospective cohort studies measuring persistent asymptomatic parasitaemia 
throughout the dry and wet seasons across different transmission intensities and populations would further elucidate the dynamics between parasite density, immunity, and serological responses.

This study demonstrates that a diverse panel of serological markers can be used to monitor malaria exposure (observed through long-lived antibody responses) and recent infection incidence (through moderate to shorterlived antibody responses). By monitoring antibody responses in a variety of ways, such as age-specific seroprevalence, the magnitude of age-stratified antibody levels, or identifying areas with clustering of aboveaverage antibody responses, these antigens have the potential to complement conventional malaria surveillance tools. Serological measures could be used as secondary endpoints alongside clinical and molecular diagnostics in the evaluation of community interventions. They could also be used for baseline stratification of individuals or communities according to their risk of exposure, or to evaluate the degree to which historical or recent malaria exposure influences study outcomes. For example, a subset of the serological markers used in this study have been used to stratify individuals in a controlled human malaria infection (CHMI) study in The Gambia, where individuals with serological evidence of higher malaria exposure were found to have higher parasite growth inhibitory activity and control infection more effectively. Microarray studies evaluating the combined use of multiple serological markers suggest that panels of at least five antigens confer greater diagnostic accuracy compared to a single marker, while panels of more than 20 confer only minor improvements in accuracy [21, 44]. Between-antigen variation in antibody detection will also exist naturally; differences in the antigenicity of recombinant constructs could be due to sequence selection or expression systems, or the choice of antigen isotypes and IgG subclasses. Multi-marker diagnostic panels may be better able to capture the breadth of antibody responses in the population. This lends strong support for the combined use of $P f$ antigens identified in this study in future diagnostic platforms. Evaluating their agreement and consistency with other diagnostic outcomes in intervention trials, including cluster randomised trials and surveillance studies, can help establish standardised serological protocols usable across a variety of epidemiological settings.

\section{Conclusions}

Serological markers can serve dual functions as indicators of malaria exposure and incidence. By monitoring age-specific sero-prevalence, the magnitude of agestratified antibody levels, or identifying groups of individuals with above-average antibody responses, these antigens have the potential to complement conventional malaria surveillance tools. Further studies, particularly cluster randomised trials, can help establish standardised serological protocols to reliably measure transmission across endemic settings.

\section{Supplementary information}

Supplementary information accompanies this paper at https://doi.org/10. 1186/s12916-020-01785-6.

\section{Additional file 1: Supplementary methods and tables.}

Supplementary methods describe the antibody acquisition model used in Figs. 4 and 5. Supplementary tables provide values for sero-prevalence, sero-conversion rates, Area Under the Antibody Acquisition curve (AUC), and logistic regression.

Additional file 2. Dataset.

\section{Abbreviations}

aOR: Adjusted odds ratio; AUC: Area Under the Antibody Acquisition Curve; $\mathrm{Cl}$ : Confidence interval; DBS: Dried blood spot; DHA-PQ: Dihydroartemisninpiperaquine; EBA175: Erythrocyte binding antigen 175 RIII-V;

Etramp5.Ag1: Early transcribed membrane protein 5; GEE: Generalised estimating equations; GEXP18: Gametocyte export protein 18;

HSP40.Ag1: Heat shock protein 40; IgG: Immunoglobulin; LLIN: Long-lasting insecticide-treated net; MDA: Mass drug administration; MFI: Median fluorescence intensity; PCD: Passive case detection; PCR: Polymerase chain reaction; Pf, P. falciparum: Plasmodium falciparum; PfAMA1: P. falciparum apical membrane antigen 1; PAMSP1 ${ }_{19}$ : P. falciparum merozoite surface antigen 1 19-kDa carboxy-terminal region; RDT: Rapid diagnostic test; Rh2.2030: Reticulocyte binding protein homologue 2; SCR: Sero-conversion rate; URR: Upper River Region, The Gambia; WCR: West Coast Region, The Gambia

\section{Acknowledgements}

Thanks for Linda Reiling and Christine Langer (Burnet Institute) for help with recombinant protein expression.

\section{Authors' contributions}

LW designed and coordinated the study, supervised and performed the serological lab work, analysed the data, and wrote the manuscript. JM and MA supervised the field data collection and laboratory work. SC and MB conducted the serological assays. KKAT, SKS, and JGB produced the antigens, advised on the interpretation of findings, and reviewed the manuscript. KKAT and TH developed the serological assay. JM, MA, UD, IK, and CD advised on the study design and interpretation of findings, and reviewed the manuscript. All authors read and approved the final manuscript.

\section{Funding}

This study was funded by the UK Medical Research Council (UKMRC) through the LSHTM Doctoral Training Programme studentship received by LW (MR/J003999/1). JGB was supported by the National Health and Medical Research Council of Australia (Investigator Grant 1173046, Program Grant 1092789). Burnet Institute is supported by the NHMRC Independent Research Institute Infrastructure Support Scheme and a Victorian State Government Operational Infrastructure grant. The funders had no role in the design of the study; collection, analysis, and interpretation of data; or writing of the manuscript.

\section{Availability of data and materials}

The datasets used and/or analysed during the current study are provided as Additional file 2, but personally identifying information on village and compound has been removed to maintain confidentiality. Access to this data can be made available from the corresponding author on reasonable request.

Ethics approval and consent to participate

This study was approved by the Gambia Government/MRC Joint Ethics Committee (SCC1318). Verbal consent was first obtained at village sensitisation meetings, followed by individual written informed consent for 
all participants. Parents/guardians provided written consent for children less than 17 years, and assent was obtained from children between 12 and 17 years.

\section{Consent for publication}

Not applicable

\section{Competing interests}

All authors declare no competing interests.

\section{Author details}

${ }^{1}$ Faculty of Infectious Tropical Diseases, Department of Infection Biology, London School of Hygiene and Tropical Medicine (LSHTM), London WC1E 7HT, UK. ${ }^{2}$ Medical Research Council Unit The Gambia at London School of Hygiene and Tropical Medicine, Fajara, The Gambia. ${ }^{3}$ Bernhard Nocht Institute for Tropical Medicine (BNITM), Arusha, Tanzania. ${ }^{4}$ St. George's University of London (SGUL), London SW17 ORE, UK. ${ }^{5}$ Department for Congenital Disorders, Statens Serum Institut, Copenhagen, Denmark. ${ }^{6}$ Centre for Medical Parasitology at Department of Immunology and Microbiology, University of Copenhagen, Copenhagen, Denmark. ${ }^{7}$ Burnet Institute, Melbourne, Victoria 3004, Australia. ${ }^{8}$ Central Clinical School, Monash University, Melbourne, Victoria, Australia. ${ }^{9}$ Department of Medicine, University of Melbourne, Melbourne, Victoria, Australia. ${ }^{10}$ Faculty of Epidemiology and Population Health, Department of Infectious Disease Epidemiology, London School of Hygiene and Tropical Medicine (LSHTM), London WC1E 7HT, UK

${ }^{11}$ School of Pathology, Wits Institute for Malaria Research, Faculty of Health Science, University of Witwatersrand, Johannesburg, South Africa.

\section{Received: 6 June 2020 Accepted: 16 September 2020}

\section{Published online: 13 November 2020}

\section{References}

1. WHO Global Malaria Programme. Malaria surveillance, monitoring \& evaluation: a reference manual: World Health Organization; 2018. Available from: http://www.who.int/malaria/publications/atoz/9789241565578/en/.

2. Oesterholt MJAM, Bousema JT, Mwerinde OK, Harris C, Lushino P, Masokoto $A$, et al. Spatial and temporal variation in malaria transmission in a low endemicity area in northern Tanzania. Malar J. 2006:5:98 [cited 2015 Aug 19] Available from: http://www.pubmedcentral.nih.gov/articlerender.fcgi?artid= 1635725\&tool=pmcentrez\&rendertype=abstract.

3. Clark TD, Greenhouse B, Njama-Meya D, Nzarubara B, Maiteki-Sebuguzi C, Staedke SG, et al. Factors determining the heterogeneity of malaria incidence in children in Kampala, Uganda. J Infect Dis. 2008;198(3):393-400. [cited 2015 May 28] Available from: http://jid.oxfordjournals.org/content/1 98/3/393.full.

4. Bousema T, Drakeley C, Gesase S, Hashim R, Magesa S, Mosha F, et al. Identification of hot spots of malaria transmission for targeted malaria control. J Infect Dis. 2010;201(11):1764-74. [cited 2015 May 29] Available from: http://jid.oxfordjournals.org/content/201/11/1764.long.

5. Bousema T, Griffin JT, Sauerwein RW, Smith DL, Churcher TS, Takken W, et al. Hitting hotspots: spatial targeting of malaria for control and elimination. PLoS Med. 2012;9(1):e1001165. [cited 2015 Jul 1] Available from: http://journals.plos.org/plosmedicine/article?id=10.1371/journal.pmed.1 001165.

6. Woolhouse MEJ, Dye C, Etard J-F, Smith T, Charlwood JD, Garnett GP, et al Heterogeneities in the transmission of infectious agents: implications for the design of control programs. Proc Natl Acad Sci. 1997:94(1):338-42. [cited 2015 Jun 30] Available from: http://www.pnas.org/content/94/1/338.long.

7. Hayes R, Moulton L. Cluster randomised trials. Boca Raton: Chapman \& Hall/ CRC Press; 2009

8. Bousema T, Stevenson J, Baidjoe A, Stresman G, Griffin JT, Kleinschmidt I, et al. The impact of hotspot-targeted interventions on malaria transmission: study protocol for a cluster-randomized controlled trial. Trials. 2013;14(1):36. [cited 2015 Jul 23] Available from: http://www.trialsjournal.com/ content/14/1/36.

9. Bautista CT, Chan AST, Ryan JR, Calampa C, Roper MH, Hightower AW, et al. Epidemiology and spatial analysis of malaria in the northern Peruvian Amazon. Am J Trop Med Hyg. 2006;75(6):1216-22. [cited 2015 Jul 1] Available from: http://www.ajtmh.org/content/75/6/1216.long

10. Ernst KC, Adoka SO, Kowuor DO, Wilson ML, John CC. Malaria hotspot areas in a highland Kenya site are consistent in epidemic and non-epidemic years and are associated with ecological factors. Malar J. 2006;5(1):78. [cited 2015 Jul 1] Available from: http://www.malariajournal.com/content/5/1/78.

11. Gaudart J, Poudiougou B, Dicko A, Ranque S, Toure O, Sagara I, et al. Spacetime clustering of childhood malaria at the household level: a dynamic cohort in a Mali village. BMC Public Health. 2006;6(1):286. [cited 2015 Jul 1] Available from: http://www.biomedcentral.com/1471-2458/6/286.

12. WHO Global Malaria Programme. A framework for malaria elimination. World Health Organization; 2017. [cited 2017 Nov 1] Available from: http:// www.who.int/malaria/publications/atoz/9789241511988/en/.

13. Noor AM, Kinyoki DK, Mundia CW, Kabaria CW, Mutua JW, Alegana VA, et al. The changing risk of Plasmodium falciparum malaria infection in Africa: 2000-10: a spatial and temporal analysis of transmission intensity. Lancet. 2014;383(9930):1739-47. [cited 2018 Jun 15] Available from: https://www.sciencedirect.com/science/article/pii/S01406 73613625660?via\%3Dihub.

14. Thomas CJ, Lindsay SW. Local-scale variation in malaria infection amongst rural Gambian children estimated by satellite remote sensing. Trans R Soc Trop Med Hyg;94(2):159-63. [cited 2018] Available from: http://www.ncbi. nlm.nih.gov/pubmed/10897355.

15. D'Alessandro U, Olaleye B, Langerock P, Aikins MK, Thomson MC, Cham MK, et al. Mortality and morbidity from malaria in Gambian children after introduction of an impregnated bednet programme. Lancet. 1995;345(8948): 479-83. [cited 2018 Jun 13] Available from: https://www.sciencedirect.com/ science/article/pii/S0140673695905820?_rdoc=1\&_fmt=high\&_origin= gateway\&_docanchor=\&md5=b8429449ccfc9c30159a5f9aeaa92ffb.

16. Snow RW, Rowan KM, Lindsay SW, Greenwood BM. A trial of bed nets (mosquito nets) as a malaria control strategy in a rural area of The Gambia, West Africa. Trans R Soc Trop Med Hyg. 1988;82(2):212-5. [cited 2018 May 21] Available from: http://www.ncbi.nlm.nih.gov/pubmed/3055456.

17. Alonso PL, Lindsay SW, Schellenberg JRMA, Keita K, Gomez P, Shenton FC, et al. A malaria control trial using insecticide-treated bed nets and targeted chemoprophylaxis in a rural area of The Gambia, West Africa: 6. The impact of the interventions on mortality and morbidity from malaria. Trans $\mathrm{R}$ Soc Trop Med Hyg. 1993;87:37-44. [cited 2018 May 21] Available from: https:// www.sciencedirect.com/science/article/pii/0035920393901740.

18. Mwesigwa J, Okebe J, Affara M, Di Tanna GL, Nwakanma D, Janha O, et al. On-going malaria transmission in The Gambia despite high coverage of control interventions: a nationwide cross-sectional survey. Malar J. 2015; 14(1):314. [cited 2018 May 12] Available from: http://www.malariajournal. com/content/14/1/314.

19. Mwesigwa J, Achan J, Di Tanna GL, Affara M, Jawara M, Worwui A, et al. Residual malaria transmission dynamics varies across The Gambia despite high coverage of control interventions. Carvalho LH, editor. PLoS One. 2017; 12(11):e0187059. [cited 2018 Feb 5] Available from: http://dx.plos.org/10.13 71/journal.pone.0187059.

20. Okebe J, Affara M, Correa S, Muhammad AK, Nwakanma D, Drakeley C, et al. School-based countrywide seroprevalence survey reveals spatial heterogeneity in malaria transmission in the Gambia. Fernandez-Reyes D, editor. PLoS One. 2014;9(10):e1 10926. [cited 2018 May 12] Available from: http://www.ncbi.nlm.nih.gov/pubmed/25338083.

21. Helb DA, Tetteh KKA, Felgner PL, Skinner J, Hubbard A, Arinaitwe E, et al. Novel serologic biomarkers provide accurate estimates of recent Plasmodium falciparum exposure for individuals and communities. Proc Natl Acad Sci U S A. 2015;112(32):E4438-47. [cited 2017 Oct 30] Available from: http://www.ncbi.nlm.nih.gov/pubmed/26216993.

22. Mwesigwa J, Achan J, Affara M, Wathuo M, Worwui A, Mohammed NI, et al. Mass drug administration with dihydroartemisinin-piperaquine and malaria transmission dynamics in the Gambia: a prospective cohort study. Clin Infect Dis. 2019;69(2):278-86. [cited 2019 Oct 3] Available from: https:// academic.oup.com/cid/article/69/2/278/5125954.

23. Wu L, Mwesigwa J, Affara M, Bah M, Correa S, Hall T, et al. Antibody responses to a suite of novel serological markers for malaria surveillance demonstrate strong correlation with clinical and parasitological infection across seasons and transmission settings in The Gambia. BMC Med [Internet]. 2020;18(1):304. Available from: https://bmcmedicine. biomedcentral.com/articles/10.1186/s12916-020-01724-5.

24. Wu L, Hall T, Ssewanyana I, Oulton T, Patterson C, Vasileva H, et al. Optimisation and standardisation of a multiplex immunoassay of diverse Plasmodium falciparum antigens to assess changes in malaria transmission using sero-epidemiology. Wellcome Open Res. 2019;4:26. Available from: https://wellcomeopenresearch.org/articles/4-26/v1. 
25. Snounou G. Genotyping of Plasmodium spp. nested PCR. Methods Mol Med. 2002;72:103-16.

26. Wipasa J, Suphavilai C, Okell LC, Cook J, Corran PH, Thaikla K, et al. Longlived antibody and $\mathrm{B}$ cell memory responses to the human malaria parasites, Plasmodium falciparum and Plasmodium vivax. Kazura JW, editor. PLoS Pathog. 2010;6(2):e1000770. [cited 2018 Jun 7] Available from: http:// dx.plos.org/10.1371/journal.ppat.1000770.

27. Kerkhof K, Sluydts V, Willen L, Kim S, Canier L, Heng S, et al. Serological markers to measure recent changes in malaria at population level in Cambodia. Malar J. 2016;15(1):529. [cited 2017 Nov 1] Available from: http:// malariajournal.biomedcentral.com/articles/10.1186/s12936-016-1576-z.

28. Drakeley CJ, Corran PH, Coleman PG, Tongren JE, McDonald SLR, Carneiro I, et al. Estimating medium- and long-term trends in malaria transmission by using serological markers of malaria exposure. Proc Natl Acad Sci U S A. 2005;102(14):5108-13. [cited 2015 Jun 5] Available from: http://www. pubmedcentral.nih.gov/articlerender.fcgi?artid=555970\&tool= pmcentrez\&rendertype $=$ abstract.

29. White MT, Griffin JT, Akpogheneta O, Conway DJ, Koram KA, Riley EM, et al. Dynamics of the antibody response to Plasmodium falciparum infection in African children. J Infect Dis. 2014;210(7):1115-22. [cited 2018 Feb 27] Available from: https://academic.oup.com/jid/article-lookup/doi/10.1093/ infdis/jiu219.

30. Stewart L, Gosling R, Griffin J, Gesase S, Campo J, Hashim R, et al. Rapid assessment of malaria transmission using age-specific sero-conversion rates. PLoS One. 2009;4(6):e6083. [cited 2015 Jun 19] Available from: http:// journals.plos.org/plosone/article?id=10.1371/journal.pone.0006083.

31. Ahmed Ismail H, Tijani MK, Langer C, Reiling L, White MT, Beeson JG, et al. Subclass responses and their half-lives for antibodies against EBA175 and PfRh2 in naturally acquired immunity against Plasmodium falciparum malaria. Malar J. 2014;13(1):425. [cited 2018 May 28] Available from: http:// malariajournal.biomedcentral.com/articles/10.1186/1475-2875-13-425.

32. Stevenson JC, Stresman GH, Gitonga CW, Gillig J, Owaga C, Marube E, et al. Reliability of School surveys in estimating geographic variation in malaria transmission in the western Kenyan highlands. PLoS One. 2013;8(10):e77641.

33. Weber GE, White MT, Babakhanyan A, Sumba PO, Vulule J, Ely D, et al. Serocatalytic and antibody acquisition models to estimate differing malaria transmission intensities in western Kenya. Sci Rep. 2017:7(1).

34. Yman V, White MT, Rono J, Arcà B, Osier FH, Troye-Blomberg M, et al. Antibody acquisition models: a new tool for serological surveillance of malaria transmission intensity. Sci Rep. 2016;6(1):19472. [cited 2017 Nov 1] Available from: http://www.nature.com/articles/srep19472.

35. Arnold BF, van der Laan MJ, Hubbard AE, Steel C, Kubofcik J, Hamlin KL, et al. Measuring changes in transmission of neglected tropical diseases, malaria, and enteric pathogens from quantitative antibody levels. Picardeau M, editor. PLoS Negl Trop Dis. 2017;11(5):e0005616. [cited 2018 Mar 27] Available from: http://dx.plos.org/10.1371/journal.pntd.0005616.

36. Stanisic DI, Fowkes FJl, Koinari M, Javati S, Lin E, Kiniboro B, et al. Acquisition of antibodies against Plasmodium falciparum merozoites and malaria immunity in young children and the influence of age, force of infection, and magnitude of response. Infect Immun. 2015;83(2):646-60. [cited 2018 Apr 30] Available from: http://www.ncbi.nlm.nih.gov/pubmed/25422270.

37. Osier FHA, Fegan G, Polley SD, Murungi L, Verra F, Tetteh KKA, et al. Breadth and magnitude of antibody responses to multiple Plasmodium falciparum merozoite antigens are associated with protection from clinical malaria. Infect Immun. 2008;76(5):2240-8. [cited 2018 Jun 10] Available from: http:// www.ncbi.nlm.nih.gov/pubmed/18316390.

38. Carneiro I, Roca-Feltrer A, Griffin JT, Smith L, Tanner M, Schellenberg JA, et al. Age-patterns of malaria vary with severity, transmission intensity and seasonality in sub-Saharan Africa: a systematic review and pooled analysis. Noor AM, editor. PLoS One. 2010;5(2):e8988. [cited 2017 Nov 1] Available from: http://dx.plos.org/10.1371/journal.pone.0008988.

39. Griffin JT, Ferguson NM, Ghani AC. Estimates of the changing age-burden of Plasmodium falciparum malaria disease in sub-Saharan Africa. Nat Commun. 2014;5(1):3136. [cited 2018 May 27] Available from: http:/www.nature.com/ articles/ncomms 4136 .

40. van den Hoogen LL, Griffin JT, Cook J, Sepúlveda N, Corran P, Conway DJ, et al. Serology describes a profile of declining malaria transmission in Farafenni, The Gambia. Malar J. 2015;14(1):416. [cited 2018 Jun 13] Available from: http://www.malariajournal.com/content/14/1/416.

41. Akpogheneta OJ, Duah NO, Tetteh KKA, Dunyo S, Lanar DE, Pinder M, et al. Duration of naturally acquired antibody responses to blood-stage
Plasmodium falciparum is age dependent and antigen specific. Infect Immun. 2008;76(4):1748-55. [cited 2018 may 12] Available from: http:// www.ncbi.nlm.nih.gov/pubmed/18212081.

42. Kinyanjui SM, Conway DJ, Lanar DE, Marsh K. IgG antibody responses to Plasmodium falciparum merozoite antigens in Kenyan children have a short half-life. Malar J. 2007;6(1):82 [cited 2018 May 28] Available from: http:// malariajournal.biomedcentral.com/articles/10.1186/1475-2875-6-82.

43. Crompton PD, Kayala MA, Traore B, Kayentao K, Ongoiba A, Weiss GE, et al. A prospective analysis of the $A b$ response to Plasmodium falciparum before and after a malaria season by protein microarray. Proc Natl Acad Sci U S A. 2010;107(15):6958-63 [cited 2016 Apr 5] Available from: http://www.ncbi. nlm.nih.gov/pubmed/20351286.

44. Longley RJ, White MT, Takashima E, Brewster J, Morita M, Harbers M, et al. Development and validation of serological markers for detecting recent Plasmodium vivax infection. Nat Med. 2020;26(5):741-9 [cited 2020 May 15] Available from: http://www.nature.com/articles/s41591-020-0841-4.

\section{Publisher's Note}

Springer Nature remains neutral with regard to jurisdictional claims in published maps and institutional affiliations.
Ready to submit your research? Choose BMC and benefit from:

- fast, convenient online submission

- thorough peer review by experienced researchers in your field

- rapid publication on acceptance

- support for research data, including large and complex data types

- gold Open Access which fosters wider collaboration and increased citations

- maximum visibility for your research: over $100 \mathrm{M}$ website views per year

At BMC, research is always in progress.

Learn more biomedcentral.com/submissions 